\title{
A sinalização da avenida Paulista como prática projetual
} The signage of Paulista Avenue
as a design practice

Wilma Ruth Temin ${ }^{1}$

Roberto Temin ${ }^{2}$

Cristiane Aun Bertoldi ${ }^{3}$ 


\section{Resumo}

O escritório paulistano Cauduro/ Martino começou suas atividades em 1964 e depois de cinquenta anos dissolveu-se. Um de seus projetos premiados foi o planejamento visual urbano para a avenida Paulista. $O$ objetivo deste artigo é, ao analisar o projeto de sinalização da avenida, evidenciar o seu processo projetual. O escritório, ao redefinir o problema apresentado pelo cliente, ampliou a problematização e entendeu o cenário como um todo inter-relacionado. Os designers criaram então parâmetros para elaboração de um sistema único que atendesse a pedestres e motoristas e suas diferentes necessidades de informação, ao se localizar e ao se movimentar. $O$ escopo do trabalho compreende um breve histórico do escritório; a apresentação do problema e sua reformulação, a elaboração de parâmetros e a solução do projeto de sinalização e seus elementos para identificação da linguagem única e da solução organizacional. E para realizar sua importância, abrange também a comparação com a paisagem atual.

Palavras-chave: processo de design; sinalização urbana; avenida Paulista.

\section{Abstract}

The São Paulo design office Cauduro/ Martino started its business in 1964 and after 50 years it dissolved. One of its prized projects was the visual planning for Paulista Avenue. The goal of this article is, whereas analyzing the signage project of the avenue, highlight the creation process. The office redefined the problem presented by the client and understood the scenario as an inter-related whole. The designers created, then, parameters for the elaboration of an integrated system which catered to pedestrians and drivers and their respective needs of information for localization and movement. The scope of the work comprehends a brief history of the office; a presentation of the problem and its reformulation, the elaboration of parameters, the final solution for the signalization and its elements for the identification of the integrated system and the organizational solution. To showcase its importance, this article encompasses a comparison with the present landscape of Paulista Avenue.

Key-words: design process; urban signage; Paulista Avenue. 


\section{Rumo ao projeto da Nova Paulista: um resumo}

Sobre o Alto do Caaguaçu, em tupi-guarani, mata grande, como era chamado o espigão, o divisor de águas entre as bacias dos rios Tietê e Pinheiros que estende-se de Perdizes ao Jabaquara e cujas águas vertem ao norte para o rio Tietê e ao sul para o rio Pinheiros, foi construída a avenida Paulista, cobrindo pouco mais de dois quilômetros dessa plataforma.

Ela foi planejada, em 1891, a pedido do engenheiro e especulador imobiliário Joaquim Eugênio de Lima que comprara terras na região visando abrir uma artéria de transporte para a cidade além, logicamente, dos interesses imobiliários no loteamento da região. Ele dividiu as terras em lotes generosos e deixou um deles para que fosse ocupado por um parque de aproximadamente 48 mil m2, projetado pelo francês Paul Villon e que se localizaria defronte, no lado oposto da avenida, ao belvedere do Trianon projetado por Francisco Ramos de Azevedo, que tinha vista para a baixada, em direção ao Tietê. Considerada, inicialmente de difícil acesso, formado por escarpas íngremes, a avenida foi sendo ocupada por casarões de imigrantes enriquecidos com a indústria nascente. (LIMA in TOLEDO, 1978, p.12)

Os palacetes, mesclados com outras construções como o Instituto Pasteur, o Gymnasio Anglo Brazilian School (hoje, Colégio São Luís), o Sanatório Santa Catarina e o Grupo Escolar Rodrigues Alves, projetado por Ramos de Azevedo em 1919, viriam a ocupar toda a avenida e ruas adjacentes.

$\mathrm{Na}$ década de 1930 as grandes casas foram sendo vendidas e seus lotes retalhados, possibilitando uma mudança na paisagem da avenida. O primeiro edifício foi construído em 1941, o Anchieta, de uso misto, na confluência da Paulista e rua da Consolação e coincidindo com o processo de verticalização, em 1950, a prefeitura demoliu o belvedere, local onde foi construído o Museu de Arte de São Paulo (MASP). Por fim, a avenida começou a ser ocupada parcialmente por edifícios residenciais ou mistos como o Conjunto Nacional e anos depois quase que inteiramente tomada pelos comerciais.

Ao longo desse processo, a avenida posicionou-se como símbolo da modernidade em São Paulo, já que foi ocupada, em parte, por edifícios projetados por Paulo Mendes da Rocha, Lina Bo Bardi e Rino Levi. Muitas das construções da avenida, além de reproduzirem os padrões funcionalistas, estabelecem uma forte e coerente sintaxe entre edifício e cidade quando liberam suas galerias para o público. Hoje, escritórios, institutos de cultura, museus, lojas, escolas, hospitais e espaços públicos como parque e calçadas generosas fazem da avenida, uma rua de usos múltiplos e de movimento ininterrupto. (LIMA, 2014)

Na década de 1970, os 28 metros de largura da avenida não eram mais suficientes para o tráfego intermitente de ônibus, caminhões e carros e em 1973, ano em que havia quase 40 edifícios em construção (CAUDURO; MARTINO; REZENDE, 1974), o arquiteto Roberto Cerqueira Cesar, presidente da recém-criada Empresa Municipal de Urbanização (EMURB), anunciou um programa de obras que vinha sendo pensado ha mais de uma década (O ESTADO, 1973). A ideia da Nova Paulista seguia o projeto básico preparado pelo engenheiro e prefeito nomeado, na época, 
José Carlos de Figueiredo Ferraz, que propunha alargar a rua e criar duas avenidas: uma, superior, para circulação e outra inferior para o tráfego veloz. E abaixo da pista inferior, seria construído o túnel para o metrô. Era um projeto custoso e logo foi abandonado.
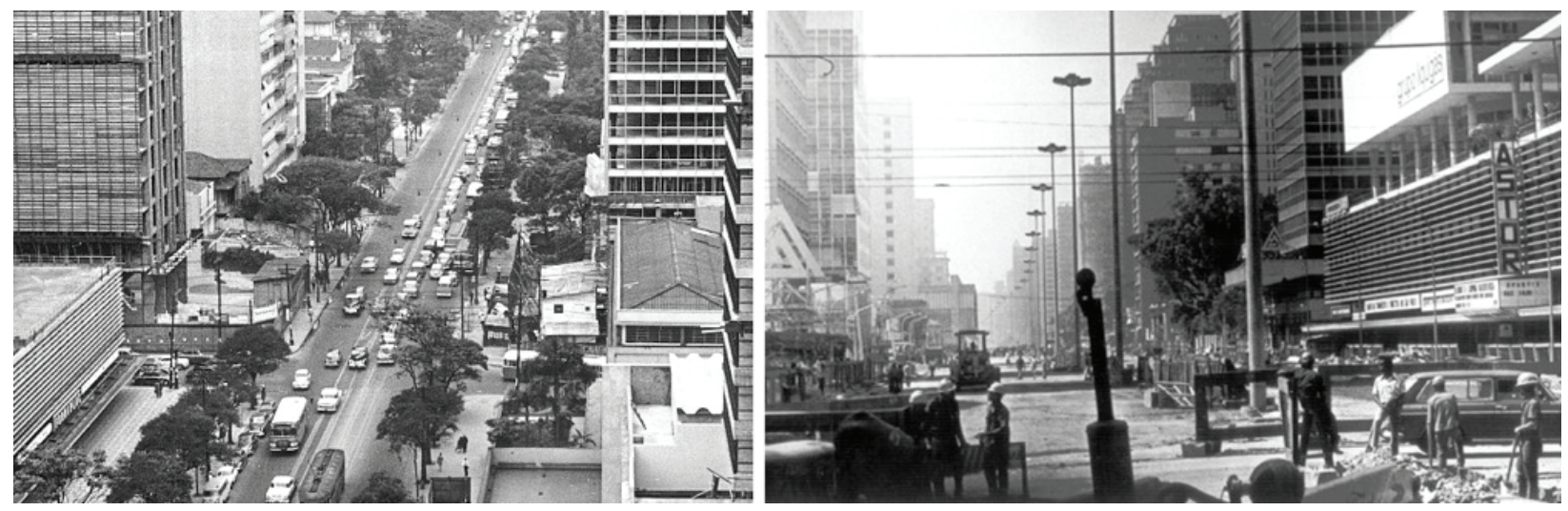

Figura 1 - Avenida Paulista com três pistas, árvores e largas calçadas (1966) e a avenida em obras (1974) Fontes: < https://commons.wikimedia.org/wiki/File:Avenida_Paulista_1970.jpg> e $<$ http://www.saopauloinfoco.com.br/a-nova-paulista-e-o-calcadao-que-nao-deu-certo/>

$\mathrm{Na}$ verdade, o que aconteceu após quase dois anos de obras, apareceu resumido em uma manchete de jornal: "O melancólico primeiro dia da nova Paulista". Sucedendo o título, o texto discorria sobre a avenida sendo entregue inacabada aos cidadãos "No lugar daquilo que o prefeito chama de 'rua padrão' havia apenas a desolação de uma obra inacabada". O texto enfatizava a falta de solução para o trânsito e continuava: "... as calçadas poderão ser concluídas em 20 dias para que se inicie a implantação do projeto de paisagismo, que custará quase três milhões e 500 mil cruzeiros e o de planejamento visual, encomendado pela Prefeitura por mais de um milhão e 100 mil cruzeiros". Mais adiante o jornalista continuava:

[...] e será, mais uma vez, uma avenida esperando a solução que, pelo menos agora, não foi adotada. Em compensação, dois projetos de paisagismo e comunicação visual que, juntos, custaram quase cinco milhões de cruzeiros, deverão transformá-la, pelo menos numa bem decorada avenida. [...]

Nas calçadas, haverá sinalização especial para alertar os pedestres de entradas e saídas de garagens; direção a seguir rumo a determinadas ruas. Para complementar o projeto, há desenhos especiais de bancas de jornais e até lanchonetes que poderão ser instaladas nas calçadas. (O ESTADO, 1974, p. 20)

\section{0 escritório Cauduro/Martino, desde o início, focado no ele- mento único}

Apesar do projeto da Nova Paulista ter sido originalmente criado com foco exclusivo na melhoria da circulação de veículos na cidade, o momento foi de oportunidade para que um projeto pioneiro de planejamento visual urbano em São Paulo acontecesse. Abriu-se espaço para o trabalho da arquiteta Rosa Grena Kliass, responsável pelo projeto paisagístico e João Carlos Cauduro e Ludovico Antonio Martino responsáveis pelo projeto de sinalização e mobiliário urbano.

O escritório Cauduro/Martino iniciara suas atividades em 1964. Os sócios, re- 
cém-graduados pela FAUUSP faziam parte de uma geração de estudantes de formação acadêmica generalista que pôde ver que a intervenção no espaço não era uma utopia ao testemunhar a inauguração de Brasília. Em meados dos anos 1960, Ludovico e João Carlos, já como professores da Universidade, cursaram as aulas de pós-graduação sobre Metadesign do professor convidado Andries Van Onk que havia estudado em Ulm, frequentaram a disciplina Comunicação de massas ministrada por Umberto Eco e assistiram também os cursos Evolução Urbana e Introdução à teoria da comunicação. (DIAS, 2015)

Em 1967, o escritório ganhou o concurso para projetar a identidade visual das Indústrias Villares, a solução deveria contemplar uma família de marcas para as organizações pertencentes ao grupo e possibilitar a criação de novas marcas para as empresas que viessem a ser criadas. Foi a hora de colocar na prática as teorias recém-apreendidas, a proposta criada pelo escritório apresentava um sistema de marcas gerado originalmente por seis quadrados. (LONGO, 2007). Foi nesse projeto que pela primeira vez o escritório usou como elemento de sinalização externa um totem com escrita vertical e segundo João Carlos: "Foi ali que começamos a perceber que o suporte da mensagem era o elemento que realmente podia criar convívio com o universo. E também que podia ser elemento de poluição da paisagem. Notamos então que quanto menor o suporte, quanto mais simples, melhor." (ARCOWEB, 2005)

No projeto para a Companhia do Metropolitano de São Paulo - Metrô, iniciado na mesma época, o objetivo dos arquitetos foi integrar todos os elementos visuais em um conjunto coerente e visava, através das mensagens visuais, garantir ao usuário uma orientação precisa durante o seu percurso. (CAUDURO; MARTINO; REZENDE, 1971). O poste usado para sinalização externa, de base triangular, apresentava a marca do Metrô, o nome da estação escrito verticalmente e a cor da linha a qual pertencia o trem que passava por ela.

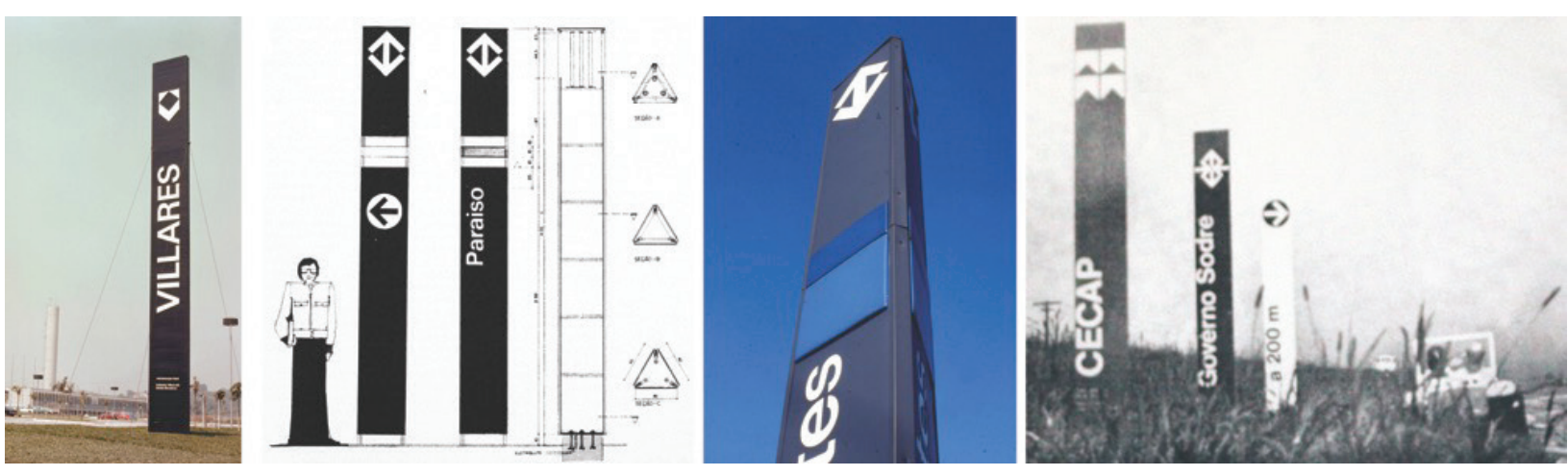

Figura 2 - Sinalização do Grupo Villares, sinalização do Metrô de São Paulo e sinalização da CECAP Fontes: Acervo Cauduro/Martino; A CONSTRUÇÃO (1973); acervo Cauduro/Martino e CAUDURO; MARTINO; REZENDE (1971)

Em 1969, a Caixa Estadual de Casas para o Povo (CECAP), uma autarquia do governo paulista, requereu um projeto de sinalização para a entrada de um conjunto habitacional na Via Dutra. O escritório propôs o uso de três postes verticais com cores distintas conforme o tipo de informação: um para a marca e nome do empreendimento, em branco sobre fundo azul; outro para a marca e o nome do governo Sodré, em branco sobre fundo vermelho e outro com fundo branco indicando a direção e a distância para a entrada. Levando em consideração que seriam posicionados ao lon- 
go de uma rodovia, eles foram projetados para serem visualizados pelos motoristas a um quilômetro de distância. (CAUDURO; MARTINO; REZENDE, 1971).

\title{
3 A sinalização da Avenida Paulista como prática projetual a par- tir da leitura de um sistema
}

Em 1971, na revista Acrópole, o escritório havia publicado o seu pensamento sobre mensagens visuais na cidade:

\begin{abstract}
Fazer planejamento visual é organizar e programar o espaço urbano, entendido como campo para a transmissão de mensagem.

A ausência de planejamento colocou coisas erradas em lugares errados. A falta de organização das mensagens anula seu principal objetivo: informar [...] Só o planejamento visual urbano pode prever e evitar o ruído, gerando mensagens e suportes eficazes. Capazes de combater a desordem visual urbana. (CAUDURO; MARTINO; REZENDE, 1971, pp. 8-9)
\end{abstract}

Dois anos depois, foi como se a requisição de um projeto de sinalização e mobiliário urbano para a avenida Paulista tivesse vindo de encontro às ideias desses projetistas ansiosos pela ordem visual.

Em um processo de aprimoramento dos trabalhos anteriores, o projeto de planejamento visual encomendado pela prefeitura de São Paulo foi a oportunidade de ampliar e colocar em prática o pensamento do escritório, ainda que apresentasse o desafio de ser implantado em tempo recorde, três meses para a elaboração do projeto e outros três para a produção e implantação de todos os seus componentes. (LONGO, 2007)

Até então a sinalização da avenida estava a cargo das administrações regionais da cidade (DECRETO, 1973) e no ensejo de melhorar a circulação, colocavam ainda mais e maiores placas para os motoristas e nenhuma indicação para os pedestres. $E$, claramente, não havia um padrão de execução. As placas que indicavam aos motoristas que os caminhões e ônibus deviam conservar-se à direita podiam ter fundo de qualquer cor. Os tipos de letras usados nas placas que indicavam as direções a seguir para os bairros eram diferentes daquelas que indicavam a faixa correta. E pregadas nos postes dos sinais semafóricos estavam as placas de formato arredondado com a indicação de proibido virar.

\section{A inter-relação homem/veículo/espaço urbano como pressu- posto do novo projeto}

Ao procurar uma solução para o problema inicial apontado pela prefeitura, o da ineficiente circulação viária, o escritório partiu não da questão apresentada mas de outros fatores: das relações homem/veículo/espaço urbano. Para identificar essas conexões foram feitas fotos, anexadas ao pré-projeto apresentado ao cliente que evidenciavam a relação do homem com o ambiente. A câmara se posicionava na altura do olhar do pedestre ao atravessar a rua ou ao observar as placas existentes. Questionando as relações, o escritório criou uma nova maneira de atuar. Ele criou 
desde o inicio do projeto uma visão original, na medida em que não focou no problema mas observou a avenida como um conjunto de relações. Depois do partido tomado, acrescentou critérios como base para seu projeto, como o de integrar as mensagens visuais e os equipamentos necessários em um conjunto uno, coerente e organizado, dotado de linguagem própria e de alto rendimento informacional.

Ao reformular o problema primário, a Cauduro/Martino entendeu que a avenida fazia parte de um todo maior e propôs como plano, um sistema, um conjunto organizado de mensagens visuais e respectivos canais de transmissão, capaz de atender às necessidades informativas dos usuários da Paulista.

Como critérios adotados para as mensagens visuais, elas deveriam satisfazer aos padrões da sinalização viária e serem capazes de garantir sua máxima eficácia, através da:

a) funcionalidade: deviam ser adequadas ao tráfego e ao fluxo de pedestres;

b) visibilidade: deviam atrair a atenção dos motoristas em distâncias adequadas e deviam distinguir-se como sinais de tráfego, não se confundindo com outras mensagens visuais urbanas;

c) legibilidade: deviam ser legíveis e compreensíveis a partir de distâncias adequadas e

d) reconhecimento: deviam ser projetadas e localizadas de forma a deixar aos motoristas, após a percepção dos sinais, tempo suficiente para tomar as decisões de tráfego com total segurança.

O pedestre, sensível ao tráfego rápido e intenso da avenida precisava assegurarse em relação aos veículos. E em relação ao espaço urbano ele precisava ter informações para posicionar-se corretamente em relação à sua localização na avenida, identificar os serviços disponíveis, as paradas e linhas de ônibus. (CAUDURO; MARTINO; REZENDE, 1974)

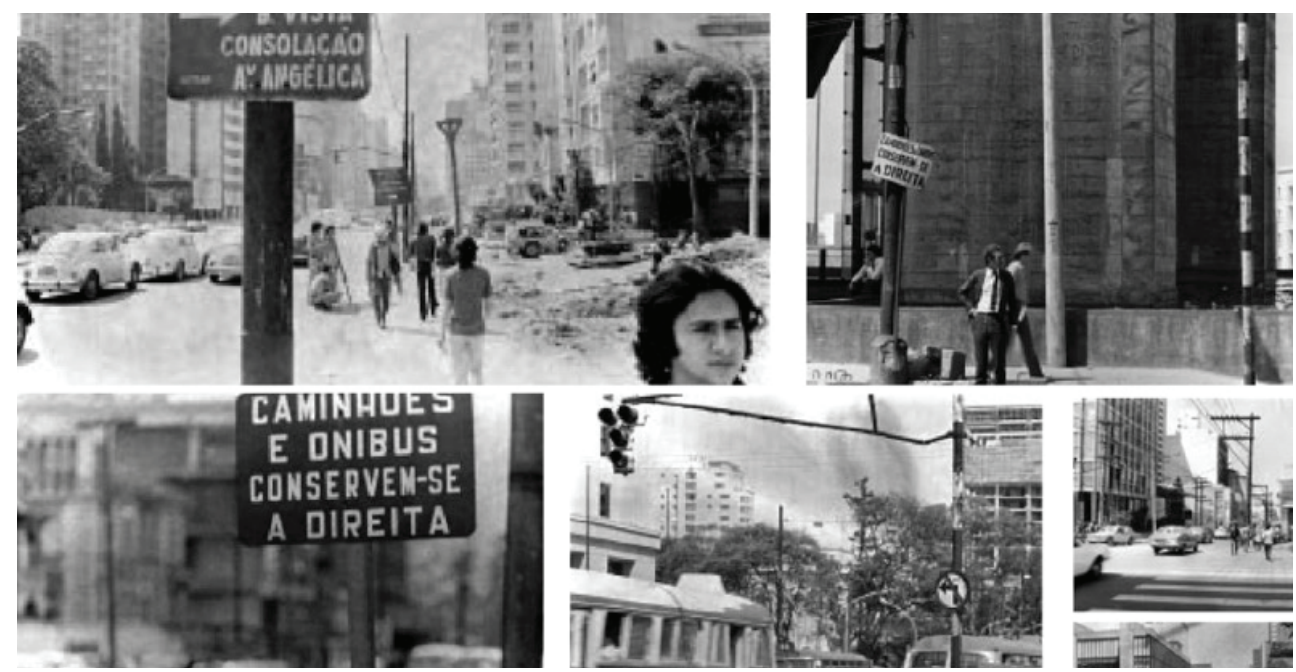

Figura 3 - Imagens do pré-projeto da avenida Paulista (1973) Fonte: LONGO (2007)

Quanto ao tráfego veicular, a avenida Paulista era tanto vista como um corredor, uma via expressa na malha urbana; como uma via de circulação local, distribuindo os carros para as transversais e para as garagens dos edifícios e casas locais. Fora isso, o 
tráfego veicular é regido por normas de trânsito determinadas pelo órgãos públicos responsáveis. O motorista, em movimento no espaço urbano, necessitava de informação em relação ao "corredor", ao sistema viário e às normas do tráfego local e ao mesmo tempo ele precisava se posicionar em relação aos demais percursos da cidade. E em relação aos pedestres, era necessário assegurar-lhes uma área de proteção.

Sobre o ambiente urbano, a própria via e suas edificações, o foco do escritório recaiu sobre a poluição visual, "percebeu-se que não importa a qualidade formal de mensagens particulares, se estas são resolvidas isoladamente, independentes, o que importa é planejar e coordenar o conjunto de mensagens urbanas" (CAUDURO; MARTINO; REZENDE, 1974). O espaço da avenida e seu entorno foi entendido como base dos canais de transmissão das mensagens dirigidas aos pedestres e motoristas. $\mathrm{Na}$ época, foi proposto também um conjunto de equipamentos urbanos e um projeto, nunca implantado, de normalização para as placas de obras e anúncios publicitários.

\subsection{Uma proposta que contemplasse o máximo de informação no mínimo de suporte}

A partir da leitura da avenida através dessa inter-relação triádica homem/veículo/espaço e dos critérios previamente estabelecidos, o escritório chegou a um modelo organizacional de mensagens em que a sinalização da avenida estaria a cargo de um único elemento. Esse elemento, prioritariamente, tinha a tarefa de informar que ele era o próprio meio, que nele estavam todas as informações. Era para a ele que a atenção dos motoristas e dos pedestres deveria se dirigir, como se ele fosse a própria mensagem.

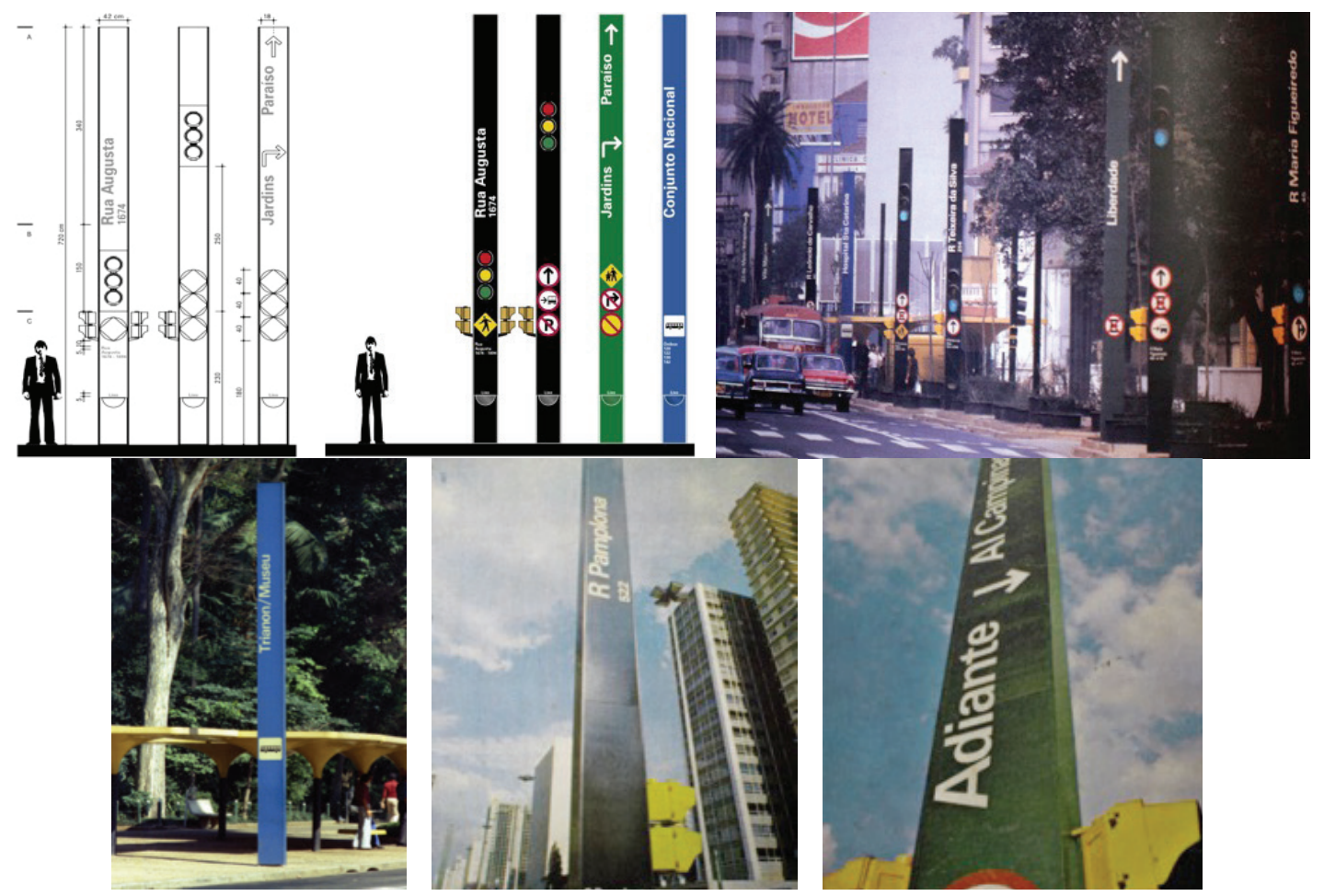

Figura 4 - Elementos do projeto para a avenida Paulista

Fontes: LONGO (2007) e foto: Lew Parrela, fonte: CAUDURO; MARTINO; REZENDE (1974) 
Determinou-se que esse elemento fosse neutro e uniforme para não poluir visualmente o espaço urbano. E que fosse contundente para criar uma identidade para a Paulista. $E$, ainda mais importante, organizasse todas as mensagens visuais.

João Carlos, em entrevista de 2005, relata: "Uma das coisas que nos parecia um contra-senso era ter num cruzamento movimentado da cidade, uma série de informações isoladas e diferentes, como nome da rua, cesto de lixo, sinais de trânsito, etc." (PROJETO, 2005)

\subsection{Em um só elemento, mensagens em três níveis de percepção}

Em relação aos usuários, o poste de uso múltiplo, enquanto transmissor de mensagens foi projetado para apresentar três níveis diferentes de percepção, distinguidos conforme a altura da colocação das informações em relação à cota do piso. Eles tinham altura total de 7,2m, por 0,42m de largura e $0,20 \mathrm{~m}$ de espessura.

Esses níveis, divididos como setores foram descritos pelos diretores do escritório em artigo da revista CJ. Arquitetura, publicada em 1974:

Setor a - nível do pedestre. Nesse nível, da cota do piso até aproximadamente 2,3m apareciam o nome da rua transversal e a numeração do quarteirão, informações sobre serviços como as linhas de ônibus, o semáforo para pedestres e outros equipamentos como caixa de correio, cesta de lixo e telefone publico.

Setor b - nível do motorista / a curta distância. Nesse setor, entre 2,3m a 3,8m a partir do solo, localizavam-se o semáforo rebatedor e os sinais de trânsito, restritos a um limite de três mensagens por poste.

Setor c - nível do motorista / a longa distância. Nesse nível, acima de 3,8m a partir da cota do piso, estavam as mensagens relativas à rua transversal, percursos e logradouros, a numeração da transversal no cruzamento e o semáforo principal, a 4,8m do solo. (CAUDURO; MARTINO; REZENDE, 1974)

\subsection{Código cromático}

Para auxiliar os motoristas a média e longa distância, foram definidas três cores diferentes de postes: os pretos, localizados nos cruzamentos, para identificar as transversais. Os verdes, indicativos de percursos, localizados no meio dos quarteirões. E os azuis, junto a hospitais ou centros comerciais da avenida, identificavam o local. Para os pedestres, os postes azuis serviam como identificação das paradas de ônibus, nesse setor havia o pictograma indicativo de parada de ônibus e as informações sobre as linhas que serviam essa parada.

\subsection{Linguagem gráfica}

A escrita vertical, que provocou polêmica na época da inauguração, tinha como partido, já adotado antes pelo escritório, a máxima legibilidade com a mínima ocupação do espaço. Na grafia das informações foi usado o tipo Univers, amplamente utilizado pelo escritório nos seus projetos anteriores. Neste caso ele era usado na 
versão bold, em negativo, com letras brancas recortadas em película adesiva e aplicadas sobre fundo escuro. Com o texto alinhado à esquerda, em caixa alta e baixa e supressão dos sinais complementares como os pontos nas abreviações, que eram sempre preferidas em relação ao uso do nome completo.

$\mathrm{Na}$ época, a avenida Paulista era entendida como uma via expressa, um "corredor" e para atender o motorista a média e longa distância o escritório calculou que seriam necessárias letras com altura de 18,5cm. Excluindo o uso da sinalização suspensa, empregada nas rodovias, já que seriam necessárias placas de dimensões colossais, optou-se pelo uso da escrita vertical, garantindo a leitura a quase $100 \mathrm{~m}$ de distância. (CAUDURO; MARTINO; REZENDE, 1974)

Ao nível da percepção dos pedestres foi usada a escrita horizontal, em tipo Univers Bold. No projeto entregue a EMURB, o escritório especificou todas as medidas dos espaçamentos entre as letras e números.

Os sinais de trânsito obedeciam ao código do Departamento de Operações do Sistema Viário (DSV) e foram redesenhados visando a aumentar sua legibilidade. Eles foram impressos por processo serigráfico com tinta reflexiva em material autoadesivo para facilitar a sua substituição. Tinham o diâmetro padronizado de 0,4m. Antes a prefeitura era obrigada a recorrer a placas de 0,8m de diâmetro. (CAUDURO; MARTINO; REZENDE, 1974). Ou seja, mesmo com a redução da área o rendimento percentual manteve-se inalterado. Sempre com o cuidado de uma linguagem gráfica coerente e padronizada.

As setas direcionais dos postes verdes indicavam os percursos possíveis estando sempre associadas ao nome dos destinos. Foram construídos geometricamente seguindo a mesma linguagem visual dos sinais de trânsito. As setas foram recortadas em adesivo branco e aplicadas.

Os pictogramas, nos postes azuis indicavam a parada de ônibus. Foram inicialmente pensados para indicar lanchonetes e outros serviços também.

A sinalização horizontal, no piso, como a faixa de ônibus e a de pedestres foi cuidadosamente planejada para ser entendida rapidamente pelos motoristas. A palavra 'bus' foi pintada sobre a avenida com uma deformação ótica em relação à tipografia original, da mesma família que a usadas nos postes, que permitisse a sua leitura em ângulo e velocidade.
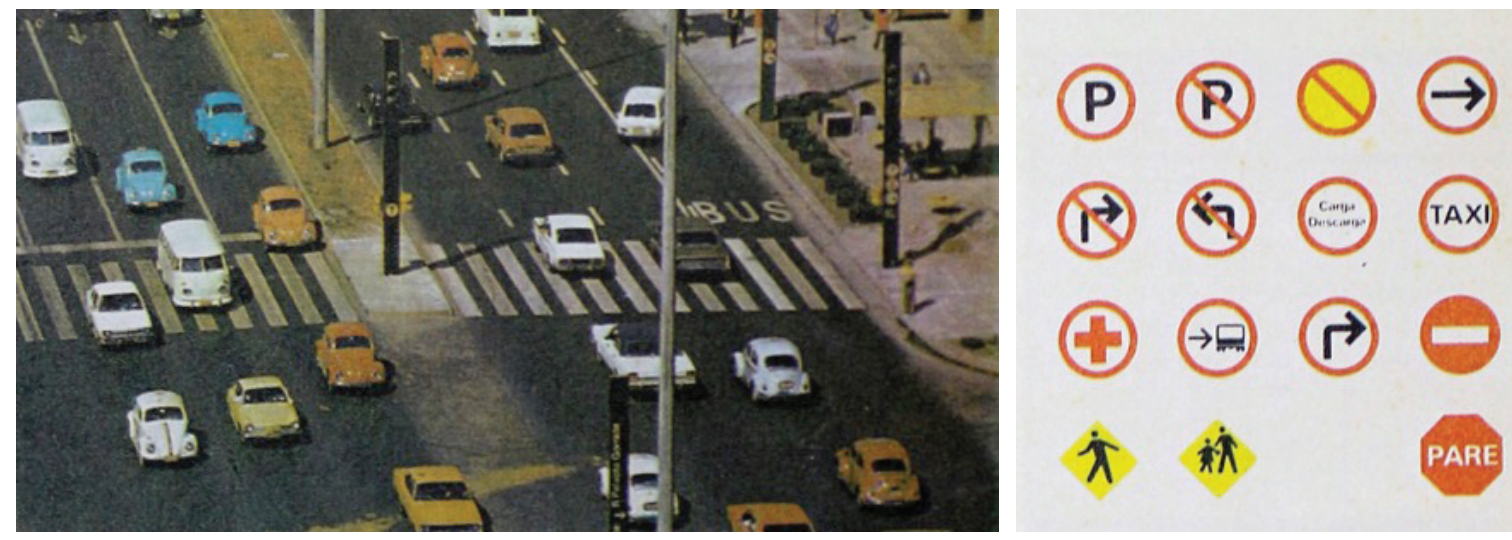

Figura 5 - Sinalização horizontal e sinais de tráfego

Foto: Lew Parrela, fonte: CAUDURO; MARTINO; REZENDE (1974) 


\subsection{Produto único}

O poste de uso múltiplo, o elemento proposto pela Cauduro/Martino, foi previsto para ser executado com perfis e treliças de aço. Por questão de disponibilidade de matéria-prima e pela possibilidade de mau acabamento resultante dos cortes feito com maçarico, o escritório optou por uma estrutura composta por dois perfis extrudados de alumínio em duplo T que formavam uma viga Vierendeel oferecendo melhores características estético-estruturais e possibilitando a criação de um vão no seu interior. Foi preciso, na época, recorrer a Alcan, no norte do País para a extrusão dos perfis e depois, na montagem, houve necessidade da presença de um funcionário do escritório na empresa contratada para que os postes fossem executados conforme as especificações.

Durante dois meses trabalhou-se intensamente, disse João Carlos, que só viu os postes prontos, já colocados, na própria avenida (LONGO, 2007). Com estrutura e revestimento em alumínio, os postes, tinham uma estrutura que, segundo o arquiteto, apenas entortava e não caia ao se atingida por algum veículo (IZIDORO, 2005). Eles eram pintados com uma tinta que permitia a adesivagem das mensagens.

O projeto construtivo dos postes possibilitava que no seu centro, oco, pudessem ser embutidos os semáforos e latas de lixo. E, parafusados, os semáforos para pedestres.
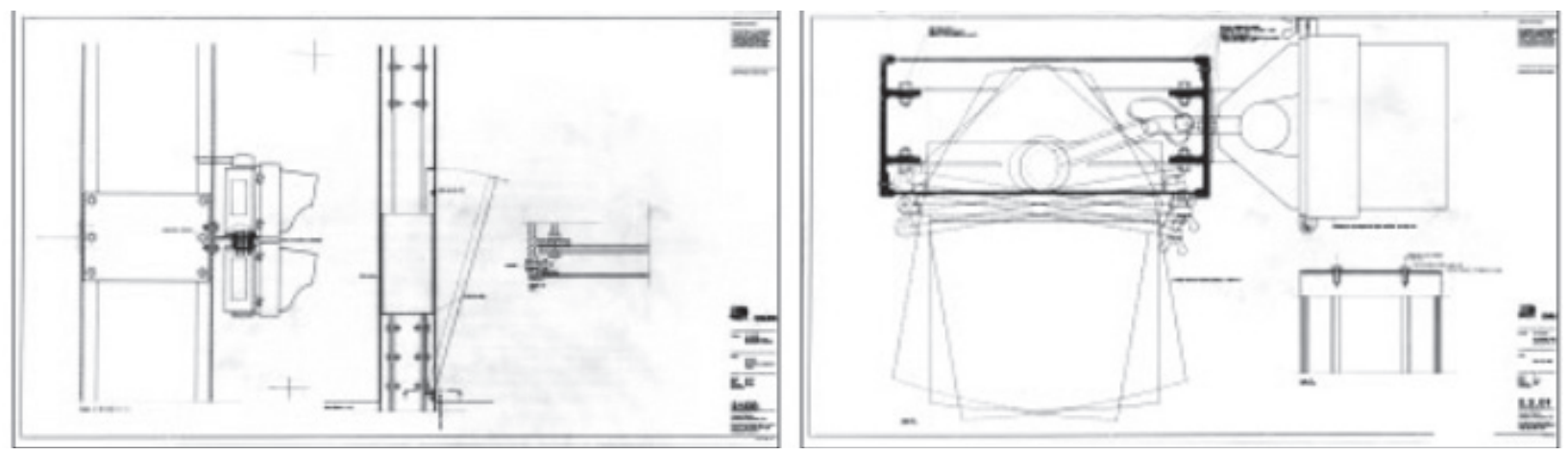

Figura 6 - Poste de uso múltiplo. Fac-símile de pranchas do projeto executivo. Lixeira e semáforo Fonte: LONGO (2007)

\subsection{Relação com o espaço urbano, localização e poluição visual}

Ao mesmo tempo que foi feita a sinalização da avenida o escritório projetou o mobiliário urbano, constituído por abrigos para as paradas de ônibus, quiosques para venda de lanches, flores ou revistas, bancos e guaritas tubulares para guardas. O mobiliário foi quase todo projetado em fibra de vidro e estrutura metálica. A sua organização no espaço, junto com a da sinalização, foi objeto de estudo do escritório para funcionassem juntas, como um projeto único, integradas. Relacionando todos esses elementos também com o projeto paisagístico em andamento no mesmo momento.

Outra medida inovadora foi o posicionamento dos pontos de ônibus no meio do quarteirão, desafogando os cruzamentos; e a colocação de postes com semáforo após as transversais que com os sinais rebatedores criava uma linha horizontal contínua, facilitando seu reconhecimento. (LONGO, 2007) 

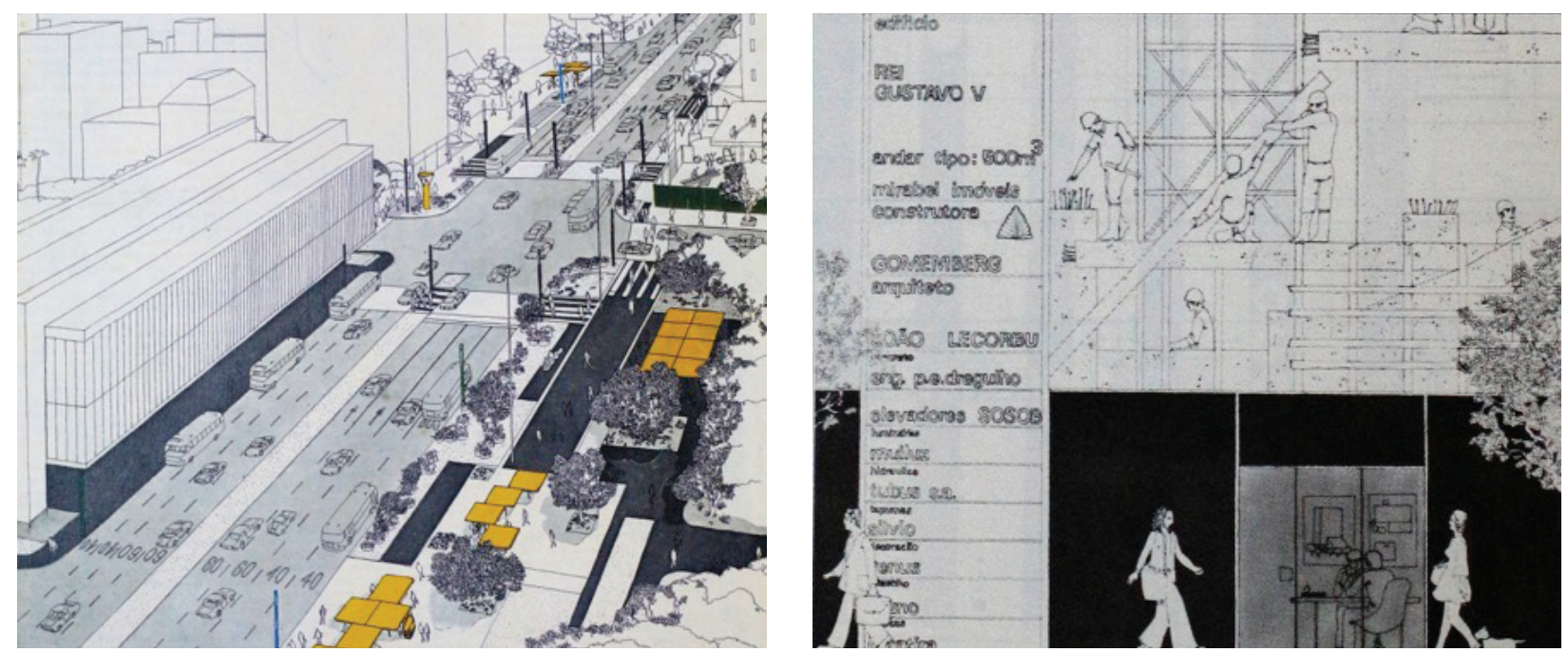

Figura 7 - Projeto de localização dos postes e mobiliário urbano e para padronização das informações sobre obras Fonte: A CONSTRUÇÃO (1974)

Além da sinalização, os meios e mensagens visuais espalhadas pela avenida como tapumes de obras e publicidade mereceram uma proposta de ordenamento que acabou não sendo aprovada pelo órgão municipal responsável, era uma proposta constituída por módulos-padrão que deveriam ser adotados ao longo de toda a avenida.

\section{Em 2018, a desinformação}

No final dos anos 1980, com a falta de manutenção, abrigos e bancos começaram a ser retirados e também alguns postes entre os cruzamentos. $O$ tipo Univers foi substituído, desapareceram os pictogramas e a sinalização viária especialmente redesenhada. Em 2003, o escritório foi contratado pela prefeitura de São Paulo para reformular a sinalização, os postes, nessa nova versão, saltariam de 142 para 200 ao longo da avenida. Nesse projeto foi incluída uma sinalização diferenciada para indicar a direção dos hospitais da região. O projeto foi entregue mas, nunca executado. (IZIDORO, 2005). Na administração seguinte, o escritório foi chamado novamente mas nem sequer acharam os projetos entregues anteriormente, relatou João Carlos. (ARCOWEB, 2005).

Com o passar dos anos os postes projetados pela Cauduro/Martino, passaram a servir como depositários de placas e semáforos, muitos deles, "pendurados" nas estruturas. No que corresponderia, no projeto inicial, ao nível de percepção do pedestre restam somente os semáforos. No denominado setor $b$, permanecem os semáforos rebatedores e os sinais de trânsito mas substituídos por diferentes formatos e linguagens gráficas. No nível perceptivo a longa distância, foram mantidos o semáforo principal e a identificação da rua transversal, acrescidos de placas de sinalização de limite de velocidade.

No centro das calçadas, foram colocados, na época da Copa do Mundo realizada no Brasil, postes metálicos com sinalização para pedestres que seguem ainda um outro padrão gráfico. As placas de sinalização para o tráfego de bicicletas, as últimas a serem afixadas, estão nos postes de iluminação. As informações são muitas e em 
múltiplos suportes. Foram criados vários sistemas de informação que formam diferentes conjuntos desorganizados. Em uma só via, as mensagens sobrepõem-se sem uma hierarquia evidente para o motorista ou pedestre, não há mais um sistema único em que ocorra uma inter-relação planejada entre os seus elementos, criando uma unidade.
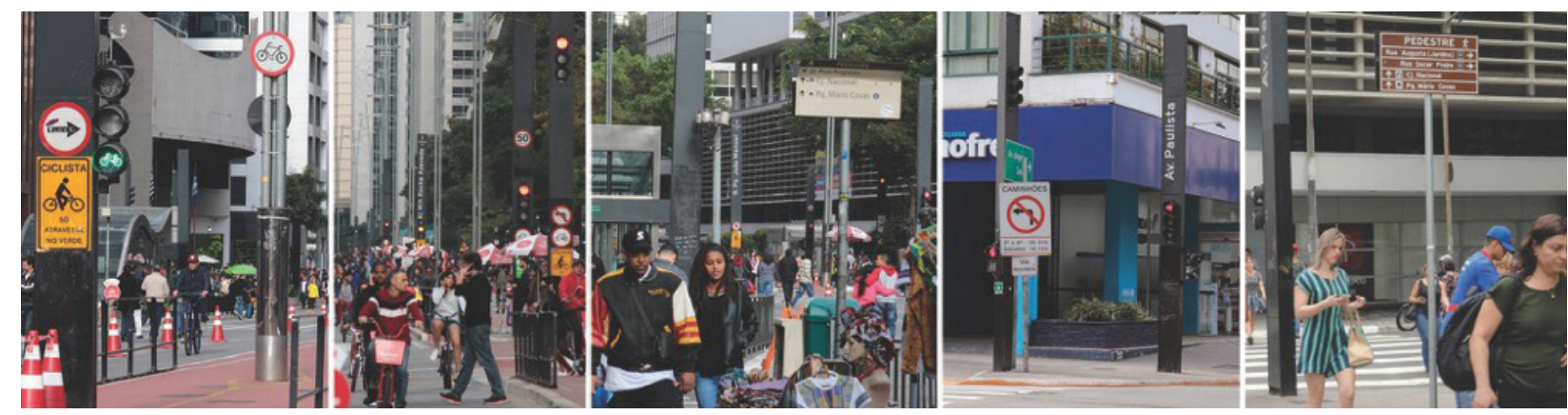

Figura 8 - Avenida Paulista em 2018

Fotos: Roberto Temin, fonte: arquivo pessoal

\section{Considerações finais}

A requisição por parte da prefeitura paulistana, na década de 1970, de um projeto de sinalização para a avenida Paulista, importante via da malha viária paulistana, cenário de tráfego intenso de pedestres e veículos, de obras em construção e de marcos arquitetônicos e turísticos da cidade, criou a oportunidade para o escritório de design Cauduro/Martino tomar um partido projetual original.

Ao redefinir o problema inicial, os designers entenderam esse cenário como um todo inter-relacionado. Não se detiveram sobre a questão do motorista e sua necessidade de movimentar-se rapidamente, meta do projeto urbano que a prefeitura encapava até aquele momento. O escritório ampliou a problematização ao basear-se na pesquisa da tríade homem/veículo/espaço urbano e suas relações, para criar um sistema de informações que atendesse às necessidades de orientação, localização e segurança de todo os usuários da avenida.

Desde o início o escritório inferiu que o projeto lidava com inúmeras variáveis e usuários distintos e que tratava com questões fundamentais como velocidade e segurança. Além de enfrentar o fato de que o projeto, assim que implantado, significaria algo novo para os cidadãos, tanto esteticamente como na maneira de usar a cidade.

Para desenvolver o projeto o escritório elegeu parâmetros próprios a serem seguidos como: funcionalidade, visibilidade, legibilidade e reconhecimento. Além daqueles estabelecidos pela EMURB e pelas leis de trânsito reguladoras. E preocupouse com a qualidade do espaço urbano enquanto cenário de mensagens visuais ora desordenadas. Da experiência de projetos anteriores, o escritório havia percebido que o poste sinalizador com sua geometria singular, deveria ser neutro e, neste caso, deveria ser o chamariz, deveria ser ele mesmo a fonte transmissora de todas as mensagens. As mensagens, por sua vez, deveriam informar, de maneira eficiente, tanto os pedestres quanto os motoristas. O suporte passaria a ter um caráter icônico, servindo de identidade para a avenida e apresentaria de maneira organizada as mensagens.

A solução, de caráter sintético, foi separar o poste com setores de informações, 
a) - o mais baixo os pedestres, b) - para os motorista e c) - para o motoristas a longa distância. O poste, neutro, era a resposta desses designers ao que os preocupavam sobremaneira no espaço urbano: a poluição visual e a desordem.

O escritório desenvolveu diferentes padrões gráficos para atingir os parâmetros inicialmente apontados para o projeto. Todas as mensagens usavam o alfabeto-padrão predeterminado, um espaçamento entre as letras previamente estudado, um código de cores próprio e localizavam-se em espaços determinados por uma malha construtiva preestabelecida. O que resultaria na eficiência da transmissão das mensagens. O escritório desenvolveu também o modelo construtivo detalhado dos postes que permitiriam a acoplagem de outros elementos como semáforos e latas de lixo.

Ao entenderem a dimensão da mudança para a cidade, os autores do projeto reformularam a questão, colocando-a como um problema de sistematização de elementos distintos e suas relações. E direcionaram-no por padrões como funcionalidade e legibilidade o que possibilitou a criação de um projeto também sistêmico, com elementos interligados e regido por padrões geradores de um todo uno que facilitasse seu entendimento pelo cidadão, possibilitando seu uso adequadamente e melhorando o trânsito da região. Foi criado um elemento sinalizador único que contém várias mensagens inter-relacionadas, um sistema fortemente integrado que potencializa a avenida Paulista como logradouro referencial da cidade.

Após décadas de descuido em relação ao projeto de sinalização original, a situação da Paulista em 2018, coberta por uma numerosa e desorganizada quantidade de informações, é uma armadilha para andarilhos, motoristas de automóveis, ônibus e bicicletas. Deixando claro como um sistema caótico de informações gera desconforto e ineficiência.

Jorge Wilheim, urbanista, declarou pouco antes de falecer: "Essa coisa do Cauduro de criar uma sinalização que é informativa e ainda assim bonita é impressionante". (O ESTADO, 2012, p. 50). E o arquiteto e professor Benedito Lima de Toledo ainda acrescenta: "...elegante e sóbrio como convém à avenida-símbolo de São Paulo." (TOLEDO, 2015)

\section{REFERÊNCIAS}

A CONSTRUÇÃO São Paulo. As mensagens que ensinarão a usar o metrô. São Paulo, Ano XXVI, no 1340, Editora Pini, 19p. 4-11., 1973.

A CONSTRUÇÃO São Paulo. A nova paisagem da Paulista. São Paulo, Ano XXVI, no 1357, Editora Pini, p. 18-23. 1974.

ARCOWEB Entrevista João Carlos Cauduro. Quando um projeto é publicado, mostramos tudo. 2005. Disponível em: https://arcoweb.com.br/projetodesign/entrevista/joao-carlos-cauduro-o-arquiteto-19-12-2005. Acesso em: 31 jan. 2018.

CAUDURO, João Carlos; MARTINO, Ludovico; REZENDE, Marco Antonio Amaral. Cauduro/Martino Arquitetos Associados. Acrópole, ano 33, n 390/391, pp. 7-36, 1971. 
CAUDURO, João Carlos; MARTINO, Ludovico; REZENDE, Marco Antonio Amaral. Av. Paulista: o design urbano. CJ. Arquitetura - Revista de Arquitetura, Planejamento e Construção, vol. 1 no 5, pp. 33-49. 1974.

DECRETO no 10.770 de 10 de dezembro de 1973. Disponível em: http://documentacao.camara.sp.gov.br/iah/fulltext/decretos/D10770. Acesso em: 31 jan. 2018.

DIAS, Dora Souza. O ensino de comunicação visual na FAU USP: história, implementação e características. São Paulo, 2015. Dissertação (mestrado). Faculdade de Arquitetura e Urbanismo da USP.

IZIDORO, Alencar. Para arquiteto projeto original não existe mais. Folha de S. Paulo, 23 de junho de 2005, p C1.

LIMA, Renata Priore. La avenida cambiante: las transformaciones de la Avenida Paulista en São Paulo y la construcción de su centralidad lineal. In: VI Seminario Internacional de Investigación en Urbanismo Barcelona-Bogotá, junio 2014. Barcelona: DUOT, 2014.

LONGO, Celso. Design total - Cauduro Martino - 1967-1977. São Paulo, 2007. Dissertação (mestrado). Faculdade de Arquitetura e Urbanismo da USP.

O ESTADO de S. Paulo. São Paulo, 5 de janeiro de 1973, p. 17.

O ESTADO de S. Paulo. São Paulo, 13 de março de 1974, p. 20.

O ESTADO de S. Paulo. São Paulo, 1 de abril de 2012, p. 50.

PROJETO Design. Entrevista com João Carlos Cauduro. São Paulo, no 309, Ed. Arco: pp. 6-8, 2005.

TOLEDO, Benedito Lima de. Símbolo da Faculdade de Arquitetura e Urbanismo da Universidade de São Paulo. Vitruvius, ano 16, 2015. Disponível em: http://www. vitruvius.com.br/revistas/read/drops/16.096/5676. Acesso em: 31 jan. 2018. 